\title{
Future distinguishing competencies of baccalaureate-educated registered nurses in nursing homes
}

\author{
Ramona Backhaus ${ }^{*}$, Hilde Verbeek, Erik van Rossum, Elizabeth Capezuti, Jan PH Hamers \\ From The European Academy of Nursing Science EANS Summer Conference \\ Barcelona, Spain. 8-9 July 2015
}

\section{Background}

In the future, working in nursing homes is likely to become more complex due to a tendency towards more personal choice, an increased complexity of residents, and technological innovations. An increase in bacheloreducated registered nurses (BRNs) might lead to an improvement in quality of life and quality of care for nursing home residents, as BRNs may be better able to deal with the increased complexity, and could have a supervisory role for less educated staff.

\section{Aims}

As BRNs are an especially scarce resource in nursing homes, obtaining more information on how to allocate them in the nursing home is desirable. To allocate them in an optimal way, the aim is to reach consensus on their future distinguishing competencies first.

\section{Methods}

Thirty-one international experts, identified through literature and our professional network, participated in a tworound web-based survey and an additional in-person focus group.

\section{Results}

Experts reached consensus on 16 desirable future distinguishing competencies. Our findings suggest the importance of competencies beyond those related to traditional nurse expert roles, e.g. being a team leader, role model and coach within the nursing team. BRNs are expected to serve as advocates of resources in the facility and to be

* Correspondence: r.backhouse@maastrichtuniversity.nl

Department of Health Services Research, Maastricht University, Maastricht, The Netherlands 